\title{
UJI KUALITATIF DAN KUANTITATIF KANDUNGAN PEMANIS BUATAN SIKLAMAT PADA SELAI ROTI DI KOTA LHOKSEUMAWE TAHUN 2016
}

\author{
S. Ranny Yulia Effendi ${ }^{1}$, Nur Fardian ${ }^{2}$, Fury Maulina ${ }^{3}$ \\ ${ }^{1}$ Program Studi Kedokteran, Fakultas Kedokteran Universitas Malikussaleh \\ ${ }^{2}$ Bagian Ilmu Gizi, Fakultas Kedokteran Universitas Malikussaleh \\ ${ }^{3}$ Bagian Ilmu Kesehatan Masyarakat, Fakultas Kedokteran Universitas Malikussaleh \\ Corresponding Author: syarifahranny227@gmail.com
}

\begin{abstract}
Abstrak
Selai merupakan makanan setengah padat yang dibuat dari buah-buahan ataupun produk olahan lain. Proses pembuatannya dapat ditambahkan bahan tambah pangan (BTP) yakni pemanis buatan, seperti siklamat. Siklamat dapat mengganggu kesehatan jika dikonsumsi dengan kadar yang melewati batas maksimumnya. Tujuan dari penelitian ini adalah untuk mengetahui adanya kandungan dan kadar siklamat pada selai roti di Kota Lhokseumawe tahun 2016. Penelitian ini bersifat deskriptif dengan menggunakan tujuh sampel selai roti yang dilakukan secara kualitatif (pengendapan) dan kuantitatif (gravimetri). Hasil penelitian ini menunjukkan bahwa seluruh sampel positif mengandung siklamat dengan kadar berkisar antara $14-70 \mathrm{mg} / \mathrm{kg}$ yang menunjukkan bahwa seluruh sampel tidak melebihi batas maksimun. Hal ini menunjukkan bahwa selai roti yang beredar di Kota Lhokseumawe tahun 2016 memenuhi persyaratan BPOM No. 4 Tahun 2014.
\end{abstract}

Kata Kunci: selai; siklamat; pemanis buatan

\section{QUANTITATIVE AND QUALITATIVE TESTS OF ARTIFICIAL SWEETENER CYCLAMATE OF JAM IN LHOKSEUMAWE 2016}

\begin{abstract}
Jam is a semi-solid food made from fruits or other processed products, which in the production process of jam, were added by additive, namely artificial sweeteners, such as cyclamate. Cyclamate can be detrimental to health if consumed over the maximum level. The purpose of this study was to determine the content and level of cyclamate in jam, within Lhokseumawe in 2016. This was a descriptive study using seven samples of jam which was done qualitatively (sedimentation) and quantitatively (gravimetric) methode. The results showed positive samples containing cyclamate with levels ranged from $14-70 \mathrm{mg} / \mathrm{kg}$ for whole samples. It showed all samples did not exceed the maximum limit and correspond to BPOM regulation No. 4 of 2014.
\end{abstract}

Keywords : jam; cyclamate; artificial sweeteners 


\section{PENDAHULUAN}

Keamanan pangan pada suatu produk makanan sangat diperlukan dalam meningkatkan kualitas pangan. Pangan yang tidak aman dapat menyebabkan penyakit yang disebut dengan foodborne diseases, yakni gejala penyakit yang timbul akibat mengkonsumsi pangan yang mengandung bahan atau senyawa beracun atau organisme patogen. ${ }^{[1]}$ Penjaminan keamanan pangan olahan membutuhkan kerjasama antara pemerintah dan produsen industri makanan yang bertujuan untuk melindungi masyarakat dari makanan dan minuman yang tidak memenuhi persyaratan keamanan pangan. ${ }^{[2]}$

Pangan yang dikonsumsi dan diterima oleh masyarakat dapat dipengaruhi oleh sifat estetika seperti rasa, warna, bau, dan tekstur. Rasa bergantung pada selera dan bau. Pangan akan terasa hambar jika tidak ada rasa. ${ }^{[3]}$ Pangan yang dikonsumsi tersebut juga dapat ditambahkan zat kimia yang dikenal sebagai Bahan Tambahan Pangan/BTP. ${ }^{[4]}$ Bahan-bahan yang ditambahkan tersebut dapat berasal dari bahan alami ataupun hasil buatan secara kimiawi yang dapat digunakan sebagai pengawet, pewarna, dan pemanis buatan. ${ }^{[5]}$

Pemanis buatan yakni salah satunya siklamat mempunyai tingkat rasa manis yang lebih tinggi dari gula biasa dan harganya yang lebih murah dibandingkan dengan gula alami, sehingga mendorong para produsen makanan dan minuman menggunakan pemanis buatan dengan tujuan mencari keuntungan. ${ }^{[2]}$ Badan Pengawas Obat dan Makanan Republik Indonesia (BPOM RI) tahun 2014 mengelompokkan pemanis buatan menjadi pemanis alami (natural sweetener) dan pemanis buatan atau sintesis (artificial sweetener). Peraturan Menteri Kesehatan Republik Indonesia Nomor 208/Menkes/Per/IV/1985 menyatakan bahwa bahan pemanis sintesis yang diperbolehkan adalah siklamat, sakarin, dan aspartame. ${ }^{[6]}$

Produk selai juga menggunakan pemanis buatan, salah satunya yaitu siklamat. ${ }^{[7]}$ Pemanis buatan siklamat mudah ditemukan di berbagai produk makanan dan minuman sehingga paling banyak digunakan di Indonesia. ${ }^{[8][9]}$ Siklamat diizinkan penggunaanya pada sejumlah makanan dan minuman di Indonesia tetapi dalam dosis yang dibatasi sesuai ketentuan. ${ }^{[10]}$ 
Penggunaan maksimum siklamat dalam miligram per kilogram bahan adalah $1000 \mathrm{mg} / \mathrm{kg}$. [5] Walaupun pemerintah sudah menetapkan peraturan mengenai penggunaan BTP, tetapi masih saja ada produsen yang menggunakan BTP yang dilarang yang dapat membahayakan kesehatan manusia. Seperti hasil penelitian yang dilakukan oleh BPOM tahun 2007 pada makanan jajan anak sekolah yang diambil dari 478 sekolah dasar di 26 provinsi terdapat 26,19\% penggunaan siklamat. ${ }^{[11]}$ Hasil tersebut seiring dengan penelitian yang dilakukan oleh Zahratulannisa tahun 2015 tentang pemanis buatan pada makanan jajanan anak sekolah di Kota Lhokseumawe yakni semua sampel (10 sampel) jajanan yang diperiksa mengandung pemanis buatan siklamat tetapi masih sesuai dengan ketentuan.

Dampak penggunaan siklamat dapat berakibat positif maupun negatif bagi masyarakat. ${ }^{[10]}$ Dampak positif siklamat yakni dapat digunakan untuk membantu dalam manajemen berat badan, pencegahan karies gigi, kontrol glukosa darah penderita diabetes melitus/DM, dan juga dapat digunakan untuk menggantikan gula dalam makanan. ${ }^{[12]}$ Dampak negatif penggunaan BTP berlebih untuk jangka pendek adalah sakit perut, diare, demam, sakit kepala, mual, dan muntah, sedangkan efek jangka panjang dapat menyebabkan memicu timbulnya kanker atau karsinogenik, gangguan saraf, gangguan fungsi hati, iritasi lambung, dan perubahan fungsi sel. ${ }^{[13]}$

BPOM belum pernah melakukan penelitian tentang kandungan pemanis buatan siklamat pada selai roti yang dijual dan diproduksi sendiri oleh Usaha Kecil Menengah/UKM di Kota Lhokseumawe. Hal ini dikarenakan sulitnya mengetahui makanan atau minuman yang dikonsumsi mengandung siklamat baik secara langsung atau tidak langsung karena rasa siklamat yang tidak memiliki rasa ikutan (after taste) seperti rasa pahit dan getir di lidah sehingga harus dilakukan identifikasi lebih lanjut di laboratorium.

Adapun yang menjadi rumusan masalah pada penelitian ini yakni karena siklamat yang merupakan salah satu pemanis buatan yang sering digunakan pada pembuatan selai roti oleh produsen di Kota Lhokseumawe dan zat tersebut dapat bersifat karsinogenik jika konsumsinya melebihi batas ketentuan BPOM, semebtara Kota Lhokseumawe merupakan salah satu konsumen selai roti tetapi penelitian mengenai pemanis buatan pada selai roti belum pernah dilakukan di Kota 
Lhokseumawe sehingga penelitian secara kualitatif dan kuantitatif mengenai siklamat pada selai roti penting untuk dilakukan.

Manfaat dari penelitian ini ditinjau secara teroritis yakni diharapkan dapat memberikan informasi tentang kadar siklamat pada selai roti yang beredar di Kota Lhokseumawe tahun 2016 sesuai dengan peraturan yang ditetapkan oleh BPOM RI Nomor 4 tahun 2014, dan secara praktis hasil penelitian ini diharapkan dapat memberikan masukan dan evaluasi tentang makanan (selai roti) bagi lembaga terkait serta dapat meningkatkan upaya food safety yang sesuai dengan Peraturan BPOM RI Nomor 4 tahun 2014 dalam hal pemakaian siklamat.

\section{METODE PENELITIAN}

Jenis penelitian yang digunakan dalam penelitian ini adalah penelitian deskriptif dengan uji laboratorium yaitu untuk mengetahui kandungan siklamat pada selai roti yang diproduksi oleh produsen selai roti di Kota Lhokseumawe tahun 2016. Lokasi pengambilan sampel dilakukan di Kota Lhokseumawe. Selanjutnya, sampel dibawa ke Laboratorium Fakultas Ilmu Matematika dan Pengetahuan Alam Universitas Syiah Kuala (FMIPA Unsiyah) untuk pengujian.

Waktu penelitian ini dilakukan pada bulan Mei 2016 sampai Maret 2017 dengan populasi penelitian yakni seluruh produsen selai roti yang diproduksi di Kota Lhokseumawe tahun 2016 yang tersebar di 4 kecamatan, yaitu Blang Mangat, Muara Satu, Muara Dua, dan Banda Sakti. Sedangkan sampel dalam penelitian ini adalah selai roti yang diproduksi di Kota Lhokseumawe tahun 2016 yang memenuhi kriteria inklusi dan eksklusi. Adapun kriteria inklusi tersebut yakni selai roti merupakan hasil produksi sendiri dan yang dijual di Kota Lhokseumawe tahun 2016 (di Market/swalayan, pasar tradisional seperti Pasar Ikan Lhokseumawe, Inpres, Cunda, Punteut, dan Batuphat, serta di usaha kecil menengah UKM (home insdustry). Sedangkat kriteria eksklusi pada penelitian ini adalah selai roti yang telah terdaftar di BPOM dan Kementerian Kesehatan Republik Indonesia (Kemenkes RI).

Pengambilan sampel pada penelitian ini dilakukan dengan cara purposive sampling, yakni pengambilan sampel yang berdasarkan atas pertimbangan yang memenuhi kriteria inklusi dan eksklusi sebagai sampel. Sampel dalam penelitian ini 
berjumlah 7 sampel dan setiap produsen dibutuhkan 1 sampel selai, yaitu: selai srikaya A, B, C, D, E, F, dan selai nenas G. Alasan pengambilan sampel tersebut adalah karena hanya 7 selai tersebut yang hanya merupakan produk buatan yang dijual di Kota Lhokseumawe yang tidak terdaftar baik di BPOM maupun di Kemenkes RI.

Adapun alat yang digunakan pada saat pengujian sampel secara kualitatif adalah eksikator, spatula, timbangan analitik, batang pengaduk, pipet ukur, serta corong gelas dan bahan yang diperlukan yakni selai roti 50 gram dan beberapa larutan seperti $\mathrm{HCl}$ $10 \% 10 \mathrm{~mL}, \mathrm{BaCl}_{2} 10 \mathrm{~mL}$, aquades, serta $\mathrm{NaNO}_{2} 10 \% 10 \mathrm{~mL}$ dan kertas saring whatman. Sedangkan alat yang digunakan pada saat pengujian sampel secara kuantitatif adalah beaker glass, kertas saring whatman, furnace, corong gelas, gelas arloji. Adapun bahan yang perlukan yakni selai roti yang merupakan selai yang positif mengandung siklamat pada uji kualitatif.

Pemeriksaan siklamat secara kualitatif dilakukan untuk mengetahui adanya kandungan siklamat dengan metode pengendapan (SNI 01-2893-1992), adapun prosedur kerjanya adalah sebagai berikut: ${ }^{[14]}$

a. Untuk keperluan laboratorium dibutuhkan 50 gram bahan yang akan diuji lalu dimasukkan ke dalam tabung reaksi $100 \mathrm{~mL}$ tambahkan $50 \mathrm{~mL}$ aquades.

b. Saring atau filtrat dengan kertas whatman.

c. Tambah $10 \mathrm{~mL} \mathrm{HCl} 10 \%$ dan $10 \mathrm{~mL} \mathrm{BaCl}_{2} 10 \%$ ke dalam filtrat, kemudian dikocok dan biarkan selama 30 menit.

d. Tambah larutan $10 \mathrm{~mL} \mathrm{NaNO}_{2}$ 10\% lalu larutan dipanaskan di atas pemanas air pada suhu $100^{\circ} \mathrm{C}$ selama 2 jam.

e. Apabila timbul endapan putih, maka kandungan siklamat pada sampel yang diteliti positif (sampel mengandung siklamat).

Sedangkan pemeriksaan secara kuantitatif dilakukan untuk menentukan kadar yang digunakan bila sampel terbukti menggunakan siklamat dengan menggunakan metode gravimetri berikut:

a. Sampel dengan hasil positif adanya kandungan siklmat disimpan di ruangan tertutup selama semalam.

b. Saring endapan dengan kertas saring whatman, dicuci, dan dikeringkan.

c. Endapan selanjutnya dipijarkan pada suhu $600{ }^{\circ} \mathrm{C}$ selama 6 jam, lalu dinginkan. 
d. Hasil endapan akhir ditimbang lalu ditimbang dengan timbangan analitik.

e. Analisis selai roti dengan metode gravimetri dengan $\mathrm{BaSO}_{4}$ (barium sulfat) sebagai endapan. Persentase kadar siklamat dihitung dengan rumus: ${ }^{[15]}$

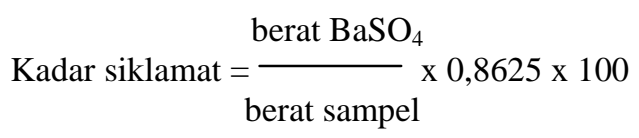

Data yang digunakan dalam penelitian ini adalah data primer. Jenis data ini merupakan data yang diperoleh langsung dari objek penelitian, dimana data tersebut merupakan hasil dari uji laboratorium selai roti terhadap siklamat.

\section{Hasil}

Sampel yang akan diuji secara kualitatif sebelumnya menjalani proses pengendapan sebanyak tiga kali, sehingga masing-masing sampel dibagi menjadi tiga bagian yang sama. Sampel tersebut masing-masing diberi kode sebagai berikut:
a. Kode selai srikaya A menjadi A1, A2, dan A3.
b. Kode selai srikaya B menjadi B1, B2, dan B3.
c. Kode selai srikaya C menjadi C1, C2, dan C3.
d. Kode selai srikaya D menjadi D1, D2, dan D3.
e. Kode selai srikaya E menjadi E1, E2, dan E3.
f. Kode selai srikaya F menjadi F1, F2, dan F3.
g. Kode selai nenas G menjadi G1, G2, dan G3.

\section{Hasil uji kualitatif siklamat pada selai roti}

Uji kualitatif dilakukan dengan cara pengendapan, yakni untuk mengetahui adanya kandungan siklamat pada selai roti tersebut. Hasil uji kualitatif ditunjukkan pada tabel berikut: 
Tabel 1. Hasil Uji Kualitatif Siklamat pada Selai Roti di Kota Lhokseumawe Tahun 2016

\begin{tabular}{ccc}
\hline Sampel & Kode Sampel & Hasil Pengamatan \\
\hline A & A1 & Endapan putih \\
& A2 & Endapan putih \\
A3 & B1 & Endapan putih \\
B & Endapan putih \\
& B3 & Endapan putih \\
C & C2 & Endapan putih \\
& C3 & Endapan putih \\
& D1 & Endapan putih \\
D & D2 & Endapan putih \\
& D3 & Endapan putih \\
& E1 & Endapan putih \\
E & E2 & Endapan putih \\
& E3 & Endapan putih \\
& F1 & Endapan putih \\
& F2 & Endapan putih \\
& F3 & Endapan putih \\
& G2 & Endapan putih \\
& & Endapan putih \\
& & Endapan putih \\
& & Endapan putih \\
& & Endapan putih \\
\hline
\end{tabular}

Sumber: Data Primer, 2017

Tabel 1. menunjukkan bahwa seluruh sampel menghasilkan endapan putih.

\section{Hasil uji kuantitatif siklamat pada selai roti}

Uji kuantitatif selanjutnya dilakukan pada sampel yang terbukti mengandung siklamat (sebanyak 21 sampel). Kemudian hasil uji kuantitatif dibandingkan dengan peraturan penggunaan siklamat yang diizinkan berdasarkan ketentuan di Indonesia. Hasil uji kuantitatif dan konversinya ( $\mathrm{mg} / \mathrm{kg}$ bahan) menurut peraturan BPOM ditunjukkan pada tabel berikut:

Tabel 2. Hasil Uji Kuantitatif Siklamat pada Selai Roti di Kota Lhokseumawe Tahun 2016

\begin{tabular}{cccc}
\hline Kode & $\begin{array}{c}\text { Berat } \\
\text { Endapan } \\
\text { Putih } \\
\text { (gram) }\end{array}$ & $\begin{array}{c}\text { Kadar } \\
\text { Siklamat } \\
\text { (gram/ } \\
50 \text { gram) }\end{array}$ & $\begin{array}{c}\text { Kadar } \\
\text { Siklamat } \\
\text { (mg/kg } \\
\text { bahan) }\end{array}$ \\
\hline A1 & 0.0015 & 0.0013 & 26
\end{tabular}




\begin{tabular}{llll} 
A2 & 0.0017 & 0.0015 & 30 \\
A3 & 0.0013 & 0.0011 & 22 \\
B1 & 1.0029 & 0.0025 & 50 \\
B2 & 0.0028 & 0.0024 & 48 \\
B3 & 0.0026 & 0.0022 & 44 \\
C1 & 0.0016 & 0.0014 & 28 \\
C2 & 0.0013 & 0.0011 & 22 \\
C3 & 0.0015 & 0.0013 & 26 \\
D1 & 0.0010 & 0.0009 & 18 \\
D2 & 0.0009 & 0.0008 & 16 \\
D3 & 0.0014 & 0.0012 & 24 \\
E1 & 0.0016 & 0.0014 & 28 \\
E2 & 0.0008 & 0.0007 & 14 \\
E3 & 0.0012 & 0.0010 & 20 \\
F1 & 0.0018 & 0.0016 & 32 \\
F2 & 0.0014 & 0.0012 & 24 \\
F3 & 0.0015 & 0.0013 & 26 \\
G1 & 0.0041 & 0.0035 & 70 \\
G2 & 0.0039 & 0.0034 & 68 \\
G3 & 0.0038 & 0.0033 & 66 \\
\hline Sul
\end{tabular}

Sumber: Data Primer, 2017

Tabel 2. menunjukkan bahwa kadar siklamat yaitu berkisar dari 14 sampai dengan $70 \mathrm{mg} / \mathrm{kg}$ bahan. Hasil ini menunjukkan bahwa kadar siklamat pada masingmasing sampel $\leq 1000 \mathrm{mg} / \mathrm{kg}$ bahan sehingga dikatakan seluruh sampel memenuhi syarat menurut BPOM.

\section{Pembahasan}

Uji kualitatif yang dilakukan pada tujuh sampel selai melalui metode pengendapan menunjukkan bahwa seluruh selai menghasilkan endapan putih. Endapan putih tersebut adalah endapan barium sulfat yang merupakan hasil dari reaksi antara natrium siklamat dengan barium klorida dan natrium nitrit. Endapan tersebut merupakan siklamat. ${ }^{[17]}$

Pengendapan dilakukan dengan cara menambahkan barium klorida $\left(\mathrm{BaCl}_{2}\right)$ dalam suasana asam kemudian ditambah natrium nitrit $\left(\mathrm{NaNO}_{2}\right)$ sehingga akan terbentuk endapan putih. Siklamat di pasar dikenal dengan nama sarimanis dan diperjualbelikan dalam bentuk asam siklamat dan garam $\mathrm{Na}$ atau $\mathrm{Ca}-n y a$ yang banyak dipakai untuk pengganti pemanis alami pada makanan atau minuman. ${ }^{[16]}$ 
Pemakaiannya banyak ditemukan terutama pada pedagang kecil dan industri rumah tangga. Hasil penelitian ini sejalan dengan penelitian yang dilakukan oleh Ayuningtias et al. (2014) yang menunjukkan bahwa seluruh selai roti menggunakan siklamat di Toko Roti Kecamatan Binjai Utara dan Binjai Kota. ${ }^{[1]}$ Penelitian lain juga pernah dilakukan oleh Mashithoh (2016) dengan hasil yakni dari lima belas sampel terdapat satu sampel yang menggunakan siklamat. ${ }^{[18]}$

Kandungan siklamat pada seluruh sampel menunjukkan hasil positif, oleh karena itu penelitian ini dilanjutkan untuk menentukan kadar siklamat pada seluruh sampel secara kuantitatif. Berdasarkan tabel 2. menunjukkan bahwa kadar seluruh sampel tidak melebihi batas yang sudah ditentukan. Penetapan kadar dilakukan secara triplo yaitu dengan tiga kali pengulangan untuk melihat keakuratan nilai kadar siklamat pada saat pemeriksaan. Penetapan kadar dengan metode gravimetri dilakukan dengan menyaring hasil reaksi (endapan) lalu mencucinya dengan air, kemudian mengeringkan endapan hasil saringan, kemudian memasukkannya ke dalam furnace yang bertujuan untuk mengabukan endapan dan selanjutnya endapan ditimbang.

Pada uji kuantitatif terdapat kadar tertinggi pada sampel G1 (70 mg/kg) dan terendah pada sampel E2 (14 mg/kg). Hasil ini menunjukkan bahwa kadar siklamat pada masing-masing sampel $\leq 1000 \mathrm{mg} / \mathrm{kg}$ bahan sehingga sampel dapat dikatakan memenuhi syarat sesuai dengan peraturan BPOM. ${ }^{[5]}$ Kadar siklamat pada penelitian ini tergolong sedikit (kurang dari 1/10 dari kadar maksimum). Kemungkinan rasa manis pada selai yang digunakan produsen sebagian besar berasasl dari pemakaian siklamat yang dicampur dengan pemakaian pemanis alami seperti gula atau sukrosa. ${ }^{[17]}$

Penelitian tentang uji siklamat pada selai juga pernah dilakukan oleh Setiawati et al. (2013) dengan hasil yakni dari delapan sampel terdapat enam sampel yang menunjukkan hasil positif penggunaan siklamat yang selanjutnya diuji secara kuantitatif yang memperlihatkan bahwa kadar siklamat memenuhi persyaratan BPOM tahun 2014 ( $\leq 1000 \mathrm{mg} / \mathrm{kg}$ bahan). ${ }^{[7]}$ Penelitian lain juga telah dilakukan oleh Astuti (2015) dengan hasil yakni dari enam sampel terdapat dua sampel positif mengandung siklamat yang selanjutnya diuji secara kuantitatif menunjukkan bahwa kadar siklamat dari dua sampel tersebut tidak memenuhi persyaratan BPOM tahun 2014 (> 1000 mg/kg bahan). Kadar 
yang didapat dari hasil uji kuantitatif yaitu pada sampel IA (7206, $251 \mathrm{mg} / \mathrm{kg}$ bahan) sedangkan pada sampel IB (7387,482 $\mathrm{mg} / \mathrm{kg}$ bahan). ${ }^{[10]}$

Adanya sampel positif mengandung siklamat memperlihatkan bahwa produsen mempunyai tujuan tertentu dalam menambahkan siklamat ke dalam selai yang mereka buat. Melalui analisis kuantitatif diketahui bahwa masih terdapat atau terdeteksi penggunaan siklamat. Hal ini dapat dipengaruhi oleh beberapa faktor, seperti faktor pendidikan yang rendah dan tidak pernah mengikuti sosialisasi atau penyuluhan tentang pengaruh dan efek yang ditimbulkan bagi kesehatan serta batas pemakaian BTP.

\section{KESIMPULAN}

Hasil penelitian tentang uji zat pemanis buatan siklamat pada selai roti di Kota Lhokseumawe tahun 2016 dengan jumlah tujuh sampel didapatkan hasil yaitu secara kualitatif dari tujuh sampel selai di Kota Lhokseumawe tahun 2016 menunjukkan bahwa seluruh sampel mengandung siklamat dengan kadar siklamat tertinggi terdapat pada sampel G1 $(70 \mathrm{mg} / \mathrm{kg})$ dan terendah pada sampel E2 $(14 \mathrm{mg} / \mathrm{kg})$ dengan rerata kadar 33,4 mg/kg. Sehingga dapat disimpulkan bahwa kadar siklamat pada seluruh sampel selai roti tidak melebihi batas maksimum berdasarkan Peraturan BPOM RI Nomor 4 Tahun 2014 tentang Batas Maksimum Penggunaan Bahan Tambahan Pangan Pemanis.

Diperlukan penelitian lebih lanjut tehadap bahan tambahan makanan lain yang terdapat dalam selai, seperti bahan pengawet, pewarna, serta pemanis lain selain siklamat (sakarin, aspartam, dan lain-lain) agar dapat terlaksananya food safety untuk suatu produk makanan karena keamanan pangan pada suatu produk makanan sangat diperlukan dalam meningkatkan kualitas pangan. Kepada produsen makanan wajib untuk mencantumkan komposisi makanan yang dijualnya sesuai dengan Keputusan Kepala BPOM RI Nomor: HK.00.05.5.1.4547 tentang Persyaratan Penggunaan Bahan Tambah Pangan Pemanis Buatan dalam Produk Pangan. Serta kepada lembaga pemerintah terkait (BPOM/Dinkes) diharapkan dapat mengadakan pemantauan secara berkala terhadap pengunaan zat pemanis serta zat tambahan makanan lain, agar para produsen dapat memahami tentang kadar-kadar BTP yang sesuai sengan peraturan sehingga dapat menjual makanan yang aman untuk konsumen. 


\section{DAFTAR PUSTAKA}

1. Ayuningtias, C., Nasution, E., Jumirah, 2014. Kajian keamanan pangan jajanan roti di toko roti Kecamatan Binjai Kota dan Binjai Utara. Staf Pengajar dan Alumni Gizi Kesehatan Masyarakat FKM USU, Medan.

2. Utomo, Y., Hidayat, A., Sasi, F. A., 2012. Studi histopatologi hati mencit (mus muskulus l.) yang diinduksi pemanis buatan. Jurnal MIPA UNNES 35(2).

3. Cahyadi,W., 2009. Analisis \& Aspek Kesehatan Bahan Tambah Pangan. Bumi Aksara, Jakarta.

4. Hasna, H., Dyah, S., 2011. Analisis kandungan nitrit dalam sosis pada distributor sosis di Kota Jakarta. Jurnal Kesmas 6(1). Universitas Ahmad Dahlan, Yogyakarta.

5. BPOM, 2004. Keamanan pangan. Buletin POM 5:5. Kemenkes RI, 1985. Peraturan Menteri

6. Kesehatan Republik Indonesia Nomor 208/Menkes/Per/IV/85 tentang pemanis buatan. Diakses dari: http://jdih.pom.go.id/.

7. Setiawati, D.A., Nurmaini, Cahaya I., 2013. Analisa kandungan natrium benzoat, siklamat, pada selai roti yang bermerek dan tidak bermerek serta tingkat pengetahuan penjual di Pasar Petisah Kota Medan Tahun 2013. Program Sarjana Fakultas Kesehatan Masyarakat Universitas Sumatera Utara, Medan.

8. Karunia F. B., 2013. Kajian penggunaan zat adiktif makanan (pemanis dan pewarna) pada kudapan bahan pangan lokal di pasar Kota Semarang. Food Science and Culinary Education Journal 2(2).

9. Novita, S., Adriyani, R., 2013. Tingkat pengetahuan dan sikap pedagang jajanan tentang pemakaian natrium siklamat dan rhodamin b. Departemen Kesehatan Lingkugan Fakultas Kesehatan Masyarakat Universitas Airlangga, Surabaya.

10. Astuti, H.G., 2015. Analisis kualitatif dan kuantitatif pemanis buatan siklamat pada selai tidak berlabel di pasar besar kota Palangkaraya tahun 2015. Program Studi D-III Farmasi Fakultas Ilmu Kesehatan Universitas Muhammadiyah Palangkaraya, Palangkaraya. 
11. Wariyah, C., Dewi, S.H.C., 2013. Penggunaan pengawet dan pemanis buatan pada pangan jajanan anak sekolah (PJAS) di wilayah Kabupaten Kulon Progo. Jurnal AGRITECH 35(2), Yogyakarta.

12. Polyak, E., Gombos, K., Hajnal, B., Bonyar-Muller, K., Szabo, S., GubiskoKisbenedek, A., Marton, K., Ember, I., 2010. Effects to artificial sweeteners on body weight, food, and drink intake. Journal of Akademiai Kiado 97(4).

13. Saparinto, C., Hidayati, D., 2010. Bahan Tambah Pangan. Kanisius, Yogyakarta. Hal: 35-36.

14. Standardisasi Nasional Indonesia (SNI), 1992. SNI 02 - 2893 - 1992. 1992. Cara Uji Pemanis Sintetis. Badan Standardisasi Nasional (BSN), Jakarta.

15. Baset, J., Denney, R., Jeffery, G., Mendham, J., 2013. Kimia Analisis Kuantitatif Anorganik. Buku Ajar Vogel diterjemahkan oleh L. Setionodan A. H Pujdjaatmaka (Edisi kelima). EGC, Jakarta.

16. Jain, T., Grover, K., 2015. Sweeteners in human nutrition. International Journal of Health Sciences and Research 5(5).

17. Standardisasi Nasional Indonesia (SNI), 2004. SNI 01-6993-2004 tentang Batas Maksimum Penggunaan Sakarin dan Siklamat Berdasarkan Kategori Pangan. Badan Standarisasi Nasional (BSN), Jakarta.

18. Mashithoh, N., 2016. Analisis kandungan zat pemanis, zat pewarna dan zat pengawet pada selai buah yang tidak bermerek yang dijual di beberapa pasar tradisional di Kota Medan [Skripsi]. Universitas Sumatera Utara, Medan. 